\title{
Adherence to Multidrug Resistant Tuberculosis Treatment and Case Management in Chongqing, China - A Mixed Method Research Study
}

This article was published in the following Dove Press journal: Infection and Drug Resistance

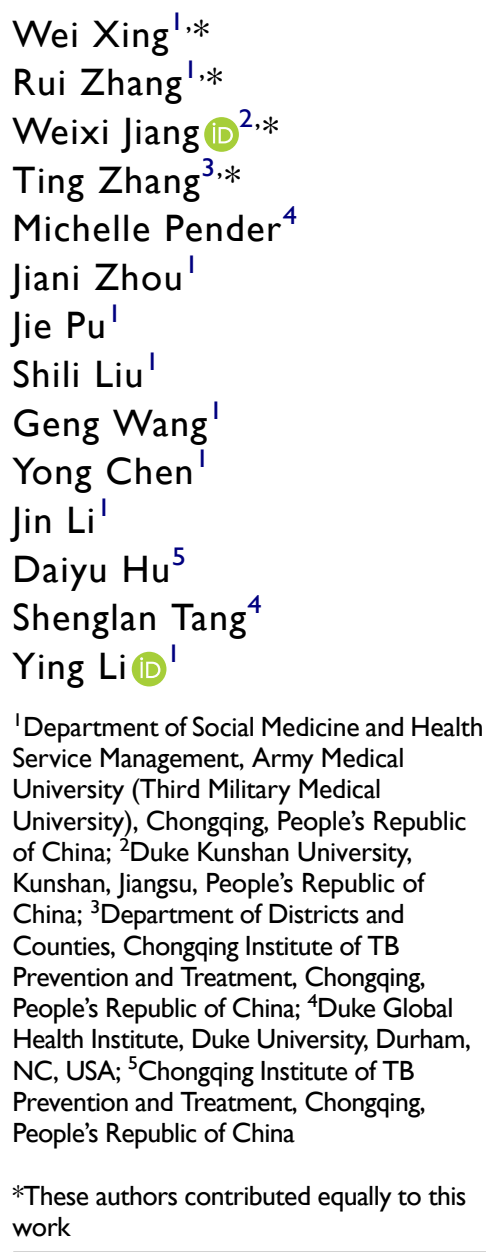

Correspondence: Shenglan Tang Duke Global Health Institute, Duke University, Durham, NC, USA

Email shenglan.tang@duke.edu

Ying Li

Department of Social Medicine and Health Service Management, Army Medical University (Third Military Medical

University), Chongqing, People's Republic of China

Email Lilyliying2012@I63.Com
Aim: This paper evaluated the treatment adherence for multidrug-resistant tuberculosis (MDRTB) and MDR-TB case management (MTCM) in Chongqing, China in order to identify factors associated with poor treatment adherence and case management.

Methods: Surveys with 132 MDR-TB patients and six in-depth interviews with health care workers (HCWs) from primary health centers (PHC), doctors from MDR-TB designated hospitals and MDR-TB patients were conducted. Surveys collected demographic and socio-economic characteristics, as well as factors associated with treatment and case management. In-depth interviews gathered information on treatment and case management experience and adherence behaviors.

Results: Patient surveys found the two main reasons for poor adherence were negative side-effects from the treatment and busy work schedules. In-depth interviews with key stakeholders found that self-perceived symptom improvement, negative side-effects from treatment and financial difficulties were the main reasons for poor adherence. MDR-TB patients from urban areas, who were unmarried, were female, had migrant status, and whose treatments were supervised by health care workers from primary health clinics, had poorer treatment adherence $(\mathrm{P}<0.05)$. Among the MDRTB patients surveyed, $86.7 \%$ received any type of MTCM in general (received any kind of MTCM from HCWs in PHC, MDR-TB designated hospital and centers of disease control/TB dispensaries and $62.50 \%$ received MTCM from HCWs in PHC sectors). Patients from suburban areas were more likely to receive both MTCM in general $(\mathrm{OR}=6.70)$ and MTCM from HCWs in MDR-TB designated hospitals $(\mathrm{OR}=2.77)$, but female patients $(\mathrm{OR}=0.26)$ were less likely to receive MTCM from HCWs in PHC sectors, and patients who were not educated about MTCM by TB doctors in designated hospitals were less likely to receive MTCM in general $(\mathrm{OR}=0.14)$. Patients who had not been hospitalized were less likely to receive MTCM from HCWs in MDR-TB designated hospitals $(\mathrm{OR}=0.21)$.

Conclusion: Stronger MTCM by HCWs in PHC sectors would improve treatment adherence among MDR-TB patients. Community-based patient-centered models of MTCM in PHC sectors and the use of digital health technology could help to improve case management and thereby improve adherence.

Keywords: multi-drug-resistant tuberculosis, management, treatment, adherence behaviors

\section{Introduction}

Tuberculosis (TB) is one of the top 10 global causes of death, and the leading cause of death from a single infectious agent. ${ }^{1}$ High rates of TB, the emergence of multidrug-resistant TB (MDR-TB) and extensively drug-resistant TB (XDR-TB) threaten global progress to end TB and meet the goals set by the World Health 
Organization (WHO)'s End TB Strategy. ${ }^{1,2}$ There were approximately 465,000 cases and 182,000 deaths from MDR/RR-TB worldwide in 2019. ${ }^{1}$ China has one of the highest rates of MDR/RR-TB in the world. In 2019, there were estimated 65,000 cases and a rate of 4.5 per 100,000 population in China; these cases constituted $14 \%$ of the global burden. ${ }^{1}$ An estimated $7.1 \%$ of new TB cases and $23 \%$ of previously treated cases developed into MDR/RRTB in 2019. ${ }^{1}$ These rates are 2.15 and 1.27 times higher than the global average, respectively. MDR-TB poses a great challenge if China is to meet the Sustainable Development Goal target of ending the TB epidemic by 2030. ${ }^{1}$ The successful treatment rate of MDR/RR-TB in China is $54 \%$, slightly lower than the global average of $57 \%{ }^{1}$ A study by S.M. Chen estimated that only $5.4 \%$ of MDR/RR-TB patients were cured nationwide in 2015, this low number has been attributed to the low diagnosis and treatment rates in China. ${ }^{3}$

Ensuring adherence to treatment is crucial to the control of MDR-TB. ${ }^{1,3-6}$ Current MDR-TB treatments typically last two years, include an eight-month intensive treatment phase followed by a further 12-month continuation phase requiring both inpatient and outpatient treatment. The MDR-TB regimen includes second-line drugs ${ }^{7}$ which have more toxicity, worse side effects, greater treatment burden (e.g. number of pills to take) and less individual efficacy compared to first-line drugs. ${ }^{8-11}$ Previous studies in China have observed poor treatment adherence behaviors including disrupted treatment courses, irregular dosing regimens and lack of timely follow-up exams. ${ }^{12-14}$ The effective management of TB patients is essential to tackle the TB crisis. MDR-TB case management (MTCM) is the assessment, planning, facilitation and coordination of a patient's health needs regarding their TB. This includes medication and appointment reminders and educating patients on how the treatment works and the importance of adherence.

The current model for TB control in most Chinese provinces has shifted away from the initial "CDC model" which required the $\mathrm{CDC}$ to provide all services related to the treatment, diagnosis and management of TB, to an "integrated model" (Figure 1) which involves a combination of the CDC, designated hospitals and primary healthcare (PHC) sectors. ${ }^{15}$ The new integrated model requires MDR-TB designated hospitals to provide inpatient MTCM, and health care workers (HCWs) in PHC sectors, including community health centres (CHCs) in urban areas as well as township hospital centres (THCs) and village clinics in rural areas to provide MTCM once patients are discharged. ${ }^{15}$ In the integrated model, MDR-TB patients should be contacted by a case manager at least once a month over the course of their twoyear treatment (24 times in total). ${ }^{16}$ Previous studies have found that treatment adherence and outcomes improve when nurses implement MTCM during the in-patient treatment

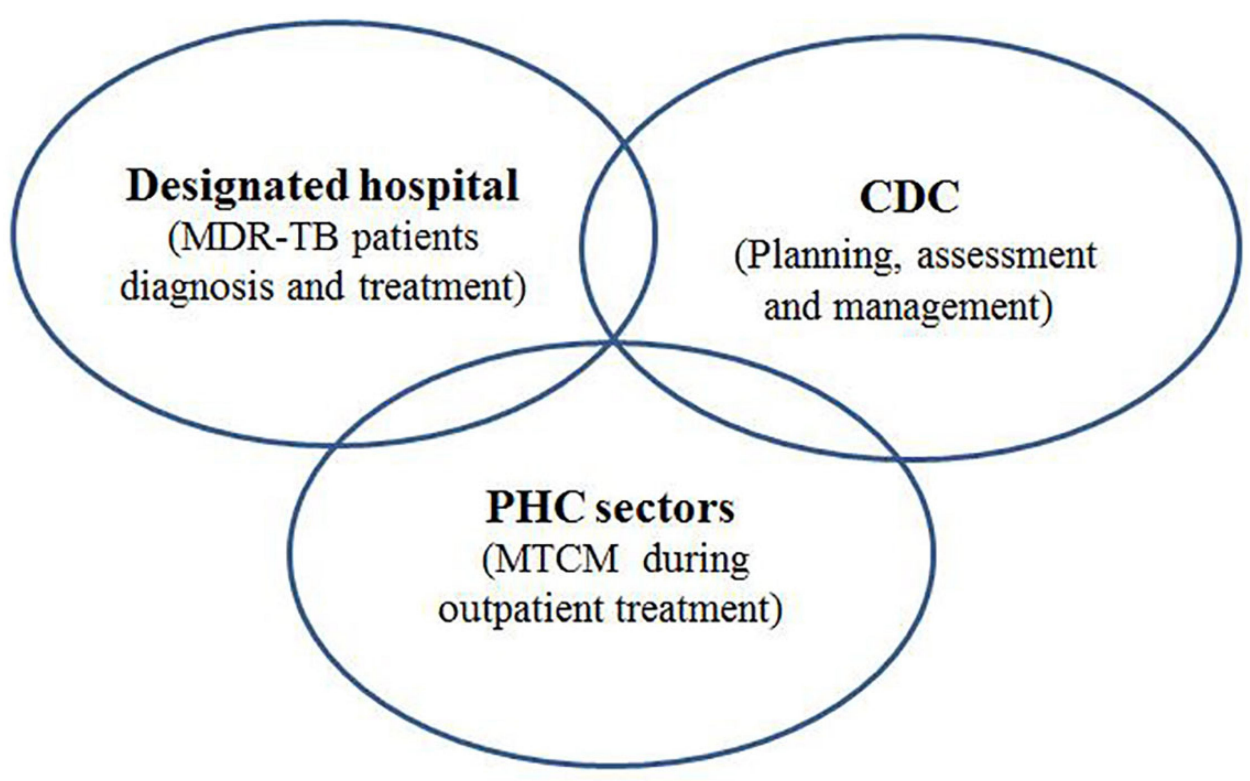

Figure I Integrated model for MDR-TB patients. This figure presents the integrated model of MDR-TB control. MDR-TB designated hospitals provide diagnosis and treatment and inpatient MTCM for MDR-TB patients. Centers for Disease Control and Prevention (CDCs) provide planning, assessment and case management related to MDR-TB control. Outpatient MTCM is mainly provided by health care workers (HCWs) in PHC sectors, including community health centres (CHCs) in urban areas as well as township hospital centres (THCs) and village clinics in rural areas. 
phase. ${ }^{17,18}$ However, few studies have focused on MTCM by HCWs in PHC sectors in China, except for one study in Zhejiang province which showed MTCM by HCWs in PHC sectors improved treatment success rates for both drug-sensitive-TB and MDR-TB, and reduced the loss-tofollow-up rate. ${ }^{19}$ Globally, studies have found that community-based MDR-TB care improves treatment initiation, ${ }^{6,20}$ and one study in South Africa indicated that communitybased MDR-TB case management achieved significant improvements in patient outcomes and resource utilization. ${ }^{21}$

This study investigated MTCM and treatment adherence of MDR-TB patients under the "integrated model" in Chongqing, China. Chongqing is a provincial-level municipality in west China and has one of the highest rates of TB in the country, including high rates of MDR-TB. MDR-TB increased from $4.6 \%$ in $2005^{22}$ to $24.55 \%$ in $2019 .^{23}$ This study examined the factors associated with poor adherence and case management. Our findings could help to improve MTCM in other similar regions with high MDR-TB burden.

\section{Methods}

A retrospective mixed-methods study was conducted using quantitative surveys and qualitative in-depth interviews. Surveys and interviews were conducted in Chongqing from December 2017 to July 2018.

\section{Quantitative Data Collection}

A consecutive sampling method was used to recruit participants for the quantitative survey. Participants were recruited when they arrived for treatment at select THCs/ CHCs if they met the following inclusion criteria: (1) Registered at a TB dispensary and diagnosed with WHO defined MDR-TB; ${ }^{1}$ (2) Received close to 2 years' standard MDR-TB treatment; and (3) Aged at least 15 years of age. Exclusion criteria included patients with intellectual impairment and patients with difficulty with speech or hearing. Participants were recruited through the CDC. All MDR-TB patients who met the inclusion criteria were approached about the study.

The survey was administered by trained investigators at district TB dispensaries or designated hospitals. The survey included information on the following: (1) sociodemographic characteristics (age, sex, occupation, ethnicity, education, registered residence, marital status, etc.); (2) MDR-TB patient treatment experience; and (3) the status of their MTCM (which included who was providing
MTCM, how often they received communication about MTCM and the methods of this communication).

A total of 145 MDR-TB patients were approached, 11 declined to participate and 134 completed the survey (92.4\% response rate), 2 patients were excluded from the final analysis based on exclusion criteria. Data from 132 MDR-TB participants were included in the final analysis.

\section{Qualitative Research}

A purposive sampling method was used to select patients for in-depth qualitative interviews. Interview participants included two purposely selected MDR-TB patients with non-adherence behaviors, two HCWs delivering TB patient management in PHC sectors, and two HCWs from MDR-TB designated hospitals. The sample size was determined by the number of participants required to reach data saturation. ${ }^{24}$

Semi-structured topic guides were used in all interviews. The topic guide for the MDR-TB patient's interview included treatment experience, the type of management received from $\mathrm{HCWs}$ in $\mathrm{PHC}$ sectors, reasons for non-adherence behaviours, and willingness to receive management from HCWs in PHC sectors. The topic guide for the HCWs' interview included questions on MDR-TB patients' behaviours related to treatment and receiving management, non-adherence and $\mathrm{HCWs}$ ' management approaches. Three senior researchers conducted the interviews in Chinese. Each interview lasted approximately 40-60 minutes. All interviews were audio-recorded and professionally transcribed for analysis.

\section{Data Analysis Quantitative Analysis}

Quantitative data were compiled in Epi Data 3.1 and analyzed in Statistical Package for Social Science (SPSS 22.0) (IBM Corporation, Armonk, NY, USA). Descriptive analysis was used to summarize participants' social-demographic characteristics, adherence to MDR-TB treatment, and MDR-TB case management. Missing data were excluded from the analysis. Study participants' key demographic characteristics such as gender, age, ethnicity and place of residence were compared with the demographic characteristics of all MDR-TB patients in Chongqing registered in the China Information System for Disease Control and Prevention (CIS-DCP) with the same treatment timeline. This comparison allowed us to examine the representativeness of the study sample. All variables were compared across MDR-TB patients with different 
adherence behaviors and MTCM using the Chi-square test. Multivariate logistic regressions of the significant variables examined the independent effects of independent factors on poor adherence behaviors and MTCM (OR and $95 \% \mathrm{CI}$ ). A two-tailed probability level of $\mathrm{p}<0.05$ was selected as the statistically significant level.

\section{Qualitative Analysis}

Each interview was transcribed and reviewed for accuracy. All in-depth interviews were analyzed using a framework approach including familiarization with the data, identifying and coding themes, and summarizing and analysing the data. ${ }^{25-27}$ Themes that were generated included: patient adherence; reasons for non-adherence; MDR-TB management by HCWs in PHC sectors; and patients' willingness to participate in case management with $\mathrm{HCWs}$ in PHC sectors.

\section{Definitions}

MDR-TB refers to the combined resistance to first-line TB drugs rifampicin and isoniazid. ${ }^{1}$ Primary healthcare (PHC) sectors in China include community health centers (CHCs) and stations in urban areas, and township hospital centers (THCs) and village clinics in rural areas. ${ }^{28}$ In the TB integrated model, CDCs are responsible for TB control, supervision, and health education; designated hospitals are responsible for TB diagnosis and treatment; and PHC sectors are responsible for case management and patient referrals. ${ }^{15}$ Further definitions are described in Appendix 1. ${ }^{1,15,16,28,29}$

\section{Results}

\section{Participant Characteristics}

This study was conducted in the 27 districts/counties in Chongqing municipality with the highest MDR-TB incidence rates. Patient demographic characteristics are shown in Table 1. In general, $43.2 \%(n=57)$ of MDR-TB participants were aged 36 to 55 years, $63.6 \%(n=84)$ were male, $57.6 \%(n=76)$ lived in suburban areas, nearly all patients $(\mathrm{n}=126 ; 95.5 \%)$ were local residents, and most were married $(\mathrm{n}=83 ; 62.0 \%)$. Almost all $(\mathrm{n}=131 ; 99.2 \%)$ patients were covered by Chinese basic medical insurance. Patients generally had low socio-economic status $(85.6 \%, n=113)$, as defined by an education level of middle school or below. $43.9 \%(n=58)$ of patients had no stable work or income and $38.7 \%(n=51)$ identified their occupation as a farmer or rural migrant worker. $59.8 \%(n=79)$ of patients lived more than two hours away from designated hospitals. Almost all patients $(97 \%, \mathrm{n}=128)$ received treatment for MDR-TB, and notably, 58.1\% $(n=68)$ received TB treatment free of charge before being diagnosed with MDRTB. Most patients $(69.5 \% \mathrm{n}=89)$ experienced a delay of a less than three days between the time of diagnosis and the time they sought treatment.

After comparing the main characteristics of study participants with other MDR-TB patients in Chongqing registered in the China Information System for Disease Control and Prevention (CIS-DCP), no differences were observed in age, gender, ethnicity and location of residence. This indicates that the MDR-TB patients included in this study could be representative of the wider population (Appendix 2).

\section{MTCM and Adherence of MDR-TB Patients}

Among the 128 patients who had ever received MDR-TB treatment, $64.1 \%(n=82)$ were still receiving treatment, $18.75 \%(n=24)$ had completed treatment, and $6.25 \%$ $(n=8)$ had interrupted treatment at the time of the survey. $40.2 \%$ received MTCM from the CDC (TB dispensaries, $50 \%$ from MDR-TB designated hospitals and 60.2\% from PHC sectors (Figure 2A); over $85 \%$ of patients had received at least one $\mathrm{MTCM}$ during their 24-month treatment period), while only $\sim 60 \%$ received the required number of contacts for MTCM for each of the 24 months.PHC sectors and designated hospitals were found to be the major providers of MTCM (Figure 2B).

For methods of MTCM delivery (Figure 2C), 73.87\% of participants received MTCM via telephone only, and around one third of the patients received these calls from HCWs in MDR-TB designated hospitals (39.64\%), PHC sectors $(34.23 \%)$ or county $\mathrm{CDC} / \mathrm{TB}$ dispensaries (33.33\%). 28.83\% patients received MTCM via both telephone and in-person home visits, mainly from HCWs in PHC sectors and county $\mathrm{CDC} / \mathrm{TB}$ dispensaries. $22.52 \%$ patients received MTCM through in-person visits to the clinic, and very few patients (9.91\%) received only inperson home visits.

As shown in Figure 3, among the 128 patients who ever received MDR-TB treatment, $62.5 \%(n=80)$ of patients were non-adherent. Specific non-adherence behaviors included missing one dose of treatment $[42.19 \%$ of the patients $(\mathrm{n}=54)]$, self-reduced drug intake [7.81\% $(\mathrm{n}=10)]$, missing the follow-up sputum examination required by the standard 
Table I Demographic, Socio-Economic and Clinical Characteristics of MDR-TB Patients in Chongqing

\begin{tabular}{|c|c|c|c|}
\hline \multicolumn{2}{|l|}{ Characteristics } & \multirow{2}{*}{ No. } & \multirow{2}{*}{$\frac{\%}{25.7}$} \\
\hline Age $(n=132)$ & $15-35$ & & \\
\hline & $36-55$ & 57 & 43.2 \\
\hline & $>55$ & 41 & 31.1 \\
\hline \multirow[t]{2}{*}{ Gender $(n=132)$} & Male & 84 & 63.6 \\
\hline & Female & 48 & 36.4 \\
\hline \multirow[t]{2}{*}{ Place of residence $(n=132)$} & Urban area & 56 & 42.4 \\
\hline & Suburban area & 76 & 57.6 \\
\hline \multirow[t]{2}{*}{ Resident status $(n=\mid 32)$} & Migrants & 6 & 4.5 \\
\hline & Resident & 126 & 95.5 \\
\hline \multirow[t]{3}{*}{ Marital status $(n=132)$} & Married & 83 & 62.9 \\
\hline & Divorced/widowed & 21 & 15.9 \\
\hline & Unmarried & 28 & 21.2 \\
\hline \multirow[t]{3}{*}{ Education $(n=132)$} & Primary and below & 40 & 30.3 \\
\hline & Middle school & 73 & 55.3 \\
\hline & College and above & 19 & 14.4 \\
\hline \multirow[t]{3}{*}{ Occupation $(n=\mid 32)$} & $\begin{array}{l}\text { Employed in enterprises/institutions/ } \\
\text { government }\end{array}$ & 23 & 17.4 \\
\hline & Peasants/rural migrant workers & 51 & 38.7 \\
\hline & Others (unstable work or no income) & 58 & 43.9 \\
\hline \multirow[t]{3}{*}{ Health insurance $(n=132)$} & $\begin{array}{l}\text { Urban Employee Basic Medical Insurance } \\
\text { (UEBMI) }\end{array}$ & 23 & 17.4 \\
\hline & Resident Basic Medical Insurance(RBMI) & 108 & 81.8 \\
\hline & No medical insurance & I & 0.8 \\
\hline \multirow{4}{*}{$\begin{array}{l}\text { Distance to the nearest drug-resistant designated hospital } \\
(n=132)\end{array}$} & $\leq 30$ minutes on foot & 4 & 3.0 \\
\hline & $\leq 2$ hours by bus & 49 & 37.1 \\
\hline & $>2$ hours by bus(round trip in one day) & 49 & 37.1 \\
\hline & $>2$ hours by bus (overnight) & 30 & 22.8 \\
\hline \multirow[t]{2}{*}{ Received MDR-TB treatment before $(n=132)$} & Yes & 128 & 97.0 \\
\hline & No & 4 & 3.0 \\
\hline \multirow[t]{2}{*}{ Received free TB treatment $(n=117) *$} & Yes & 68 & 58.1 \\
\hline & No & 49 & 41.9 \\
\hline \multirow[t]{3}{*}{ Treatment delay $(n=128) *$} & $<3$ day & 89 & 69.5 \\
\hline & $3-30$ day & 21 & 16.4 \\
\hline & $>30$ day & 18 & I4.I \\
\hline
\end{tabular}

Note: *Missing data were excluded. 


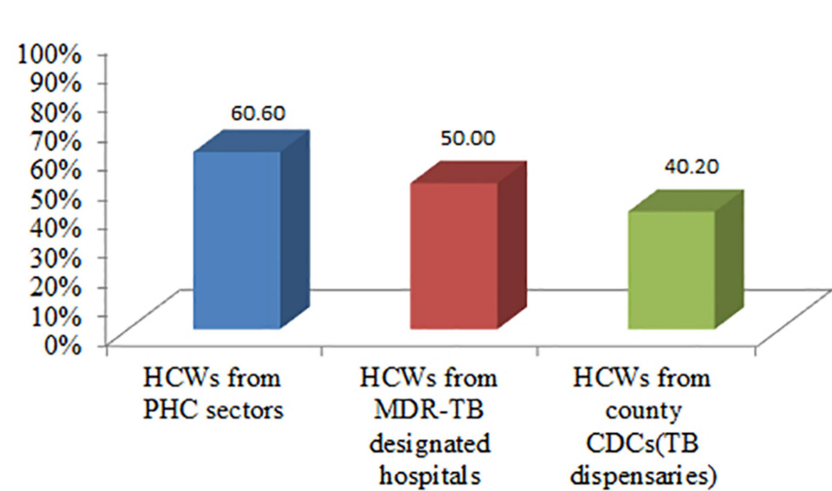

A MDR-TB case managemet providers(\%)
aCWs from $\mathrm{PHC}$ sectors

aCWs from MDR-TB designated hospitals

$\square$ HCWs from county $\mathrm{CDCs}$ (TB dispensaries)
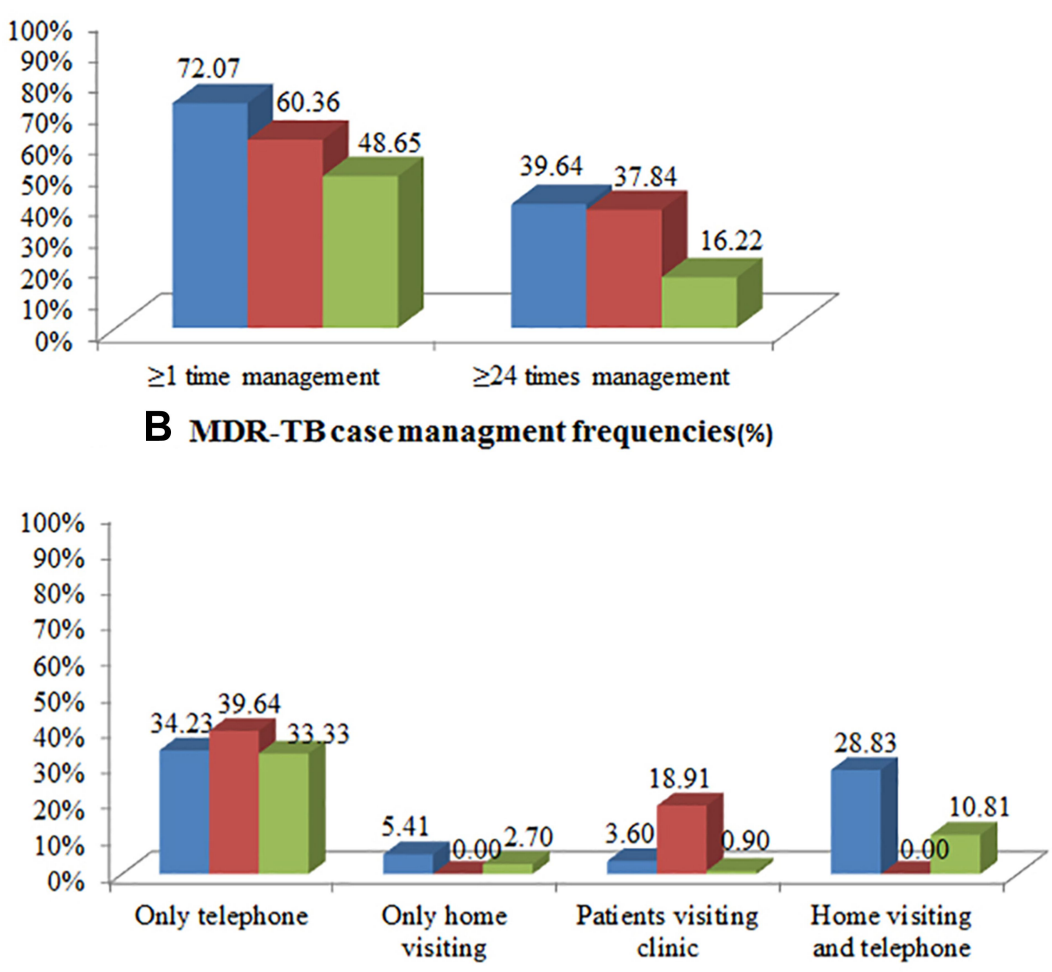

C MDR-TB treatmment management approachs(\%)

Figure 2 Status of MDR-TB case management. This figure presents the type of provider, frequency of case management contact and methods of MDR-TB case management (MTCM) by HCWs from PHC sectors, MDR-TB designated hospitals or county CDCs (TB dispensaries). (A) presents the percentage of MDR-TB patients who received MTCM from CDC (TB dispensaries), MDR-TB designated hospitals and PHC sectors. (B) presents the percentage of MDR-TB patients who received different frequencies of MTCM from HCWs from PHC sectors, MDR-TB designated hospitals or county CDCs (TB dispensaries). (C) presents the percentage of MDR-TB patients who received MTCM through the different methods.

treatment regimen $[20.31 \%(n=26)]$, and interrupted treatment $[21.87 \%(n=28)]$. The main reason given for missing dosage was a busy work schedule $(70.4 \%)$, while negative side-effects from the drugs were the main reason given for self-reduced drug intake and interrupted treatment. The three most frequently reported reasons for missing the follow-up sputum exam were: no sputum produced; financial difficulty; and the perception that it was unnecessary, each accounting for about $30 \%$.

\section{Factors Associated with MTCM and Patient Adherence to Treatment}

Results of the Univariate $\chi^{2}$ test (Appendix 3) indicated that hospitalization, living in a suburban area, learning about MTCM from HCWs in designated hospitals, and gender were all associated with MTCM $(\mathrm{p}<0.05)$. Results of the multivariate logistic regression analysis (Table 2) indicated that patients who did not learn about MTCM from HCWs in PHC sectors (OR(95\% CI): 0.14(0.03- 


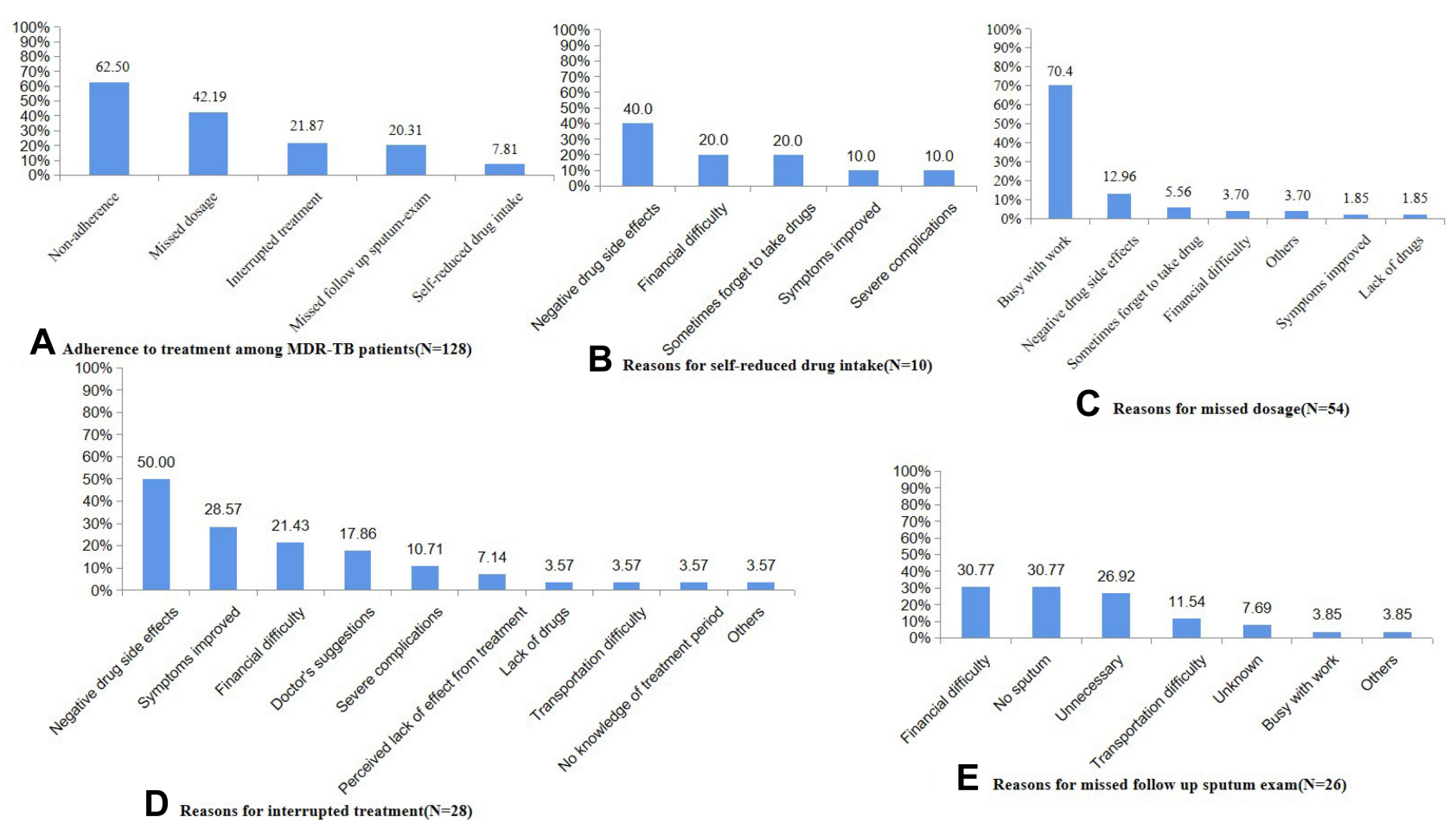

Figure 3 Status and reasons of poor adherence behaviors for MDR-TB patients. This figure presents the adherence to anti-TB treatment among MDR-TB patients (A), selfreported reasons for self-reduced drug intake (B), self-reported reasons for missed dosage (C), self-reported reasons for interrupted treatment (D), and self-reported reasons for missed follow-up sputum-exam (E).

0.74)) were less likely to receive MTCM, while patients living in sub-urban areas had a higher chance of receiving MTCM in general (OR(95\% CI): 6.70(1.52-29.55)). Female patients were less likely to receive MTCM from HCWs in PHC sectors (OR(95\% CI): 0.26(0.11-0.63)) after adjusting for other factors. Patients who had not been hospitalized were less likely to receive MTCM from HCWs in designated hospitals (OR(95\% CI): 0.21 (0.07-0.63)), while living in sub-urban areas could increase the likelihood of MTCM (OR(95\% CI): 2.77 (1.19-6.43)).

As for factors associated with adherence, results of the Univariate $\chi^{2}$ test (Appendix 4) showed that living in an urban area was associated with poor-adherence behavior $(\mathrm{P}<0.05)$. Patients aged $\geq 55$, who were migrants, had never received MTCM, were unmarried, and females were associated with poor-adherence behavior $(\mathrm{p}<0.05)$. Results of the multivariate logistic regression analysis (Table 3) showed that patients from suburban areas were less likely to be non-adherent (OR(95\% CI): 0.37(0.17$0.81)$ ). Migrants were more likely to reduce their drug intake (OR(95\% CI): 15.31(1.54-152.23)), while patients who received MTCM had a significantly lower risk of reduced drug intake (OR(95\% CI): 0.22(0.05-0.99)).
Patients who received MTCM from $\mathrm{HCWs}$ from CHCs/ THCs/villages had a higher risk of interrupted treatment (OR(95\% CI): 3.84(1.05-14.09)). Married patients (OR (95\% CI): 0.29(0.11-0.73)) were at lower risk of missing a dose, while female patients had a higher likelihood of missing their follow up sputum-exam (OR(95\% CI): 2.68 (1.09-6.60)) after adjusting for other factors.

\section{Qualitative Results About Adherence and Management}

The results from in-depth interviews are presented in Table 4. Both patients and HCWs reported that symptom improvement and negative side-effects from treatment were the main reasons for poor adherence, these findings are consistent with our quantitative results. Financial difficulty was also reported as a major reason for non-adherence since MDR-TB drugs are not necessarily covered by medical insurance, and are often very expensive.

HCWs in PHC sectors and patients expressed conflicting recollection in their interviews about the methods through which MTCM was delivered. HCWs in PHC sectors stated that they made both home visits and telephone calls to patients, however, patients stated that they only received telephone calls. Notably, HCWs in PHC 
Table 2 Multivariate Logistic Regression Analysis of MTCM

\begin{tabular}{|c|c|c|c|}
\hline Categories & $\begin{array}{c}\text { Received MTCM in } \\
\text { General }\end{array}$ & $\begin{array}{c}\text { Received MTCM from } \\
\text { HCWs from CHCs/ } \\
\text { THCs/Village }\end{array}$ & $\begin{array}{l}\text { Received MTCM from } \\
\text { HCWs from MDR-TB } \\
\text { Designated Hospital }\end{array}$ \\
\hline & OR(95\% Cl) & OR(95\% Cl) & OR(95\% Cl) \\
\hline \multicolumn{4}{|l|}{ Age } \\
\hline $15-35$ & 1 & I & 1 \\
\hline $36-55$ & $2.3 I(0.64-8.31)$ & $2.22(0.75-6.59)$ & $0.38(0.14-1.08)$ \\
\hline$>55$ & $1.38(0.38-4.98)$ & $0.89(0.28-2.89)$ & $0.49(0.16-1.52)$ \\
\hline \multicolumn{4}{|l|}{ Gender } \\
\hline Male & 1 & I & 1 \\
\hline Female & $1.50(0.47-4.80)$ & $0.26(0.12-0.63) *$ & $0.70(0.31-1.59)$ \\
\hline \multicolumn{4}{|l|}{ Health insurance } \\
\hline Urban Employee Basic Medical Insurance (UEBMI) & 1 & - & - \\
\hline Resident Basic Medical Insurance(RBMI) & $1.85(0.43-7.97)$ & - & - \\
\hline \multicolumn{4}{|l|}{ Marital status } \\
\hline Married & - & I & - \\
\hline Divorced/widowed & - & $2.20(0.74-6.57$ & - \\
\hline Unmarried & - & $0.67(0.17-2.56)$ & - \\
\hline \multicolumn{4}{|l|}{ Hospitalization } \\
\hline Yes & 1 & - & 1 \\
\hline No & $0.44(0.11-1.84)$ & - & $0.21(0.07-0.63) *$ \\
\hline \multicolumn{4}{|l|}{ Place of residence } \\
\hline Urban area & 1 & - & 1 \\
\hline Suburban area & $6.70(1.52-29.55) *$ & - & $2.77(1.19-6.43) *$ \\
\hline \multicolumn{4}{|l|}{ Educated about MTCM by HCWs in PHC sectors } \\
\hline Yes & 1 & - & - \\
\hline No & $0.14(0.03-0.74) *$ & - & - \\
\hline
\end{tabular}

Notes: $* \mathrm{P}<0.05$. "-” refers to this variable was not included in the logistic model for this independent variable.

Abbreviations: OR, odds ratio; $\mathrm{Cl}$, confidence interval; MDR-TB, multidrug-resistant tuberculosis; PHC, primary health care; MCTM, MDR-TB case management; HCWs, health care workers.

sectors stated that they provided health education to MDRTB patients, but MDR-TB patients reported they just received MDR-TB-related health education from HCWs from MDR-TB designated hospitals. These inconsistencies indicate that health education and management may not be fully implemented by HCWs in PHCs.

\section{MDR-TB Patients Expressed Different Attitudes to MTCM}

One patient expressed a strong willingness to receive case management from HCWs in PHC sectors, but another thought $\mathrm{HCW}$ s could not provide any assistance. HCWs from PHC sectors believed most MDR-TB patients accepted MTCM from them and HCWs from MDR-TB designated hospitals also thought patients trusted them; however, HCWs from both PHC sectors and MDR-TB designated hospitals stated that some patients were not willing to receive MTCM, particularly younger patients who refused due to social stigma associated with TB.

\section{Discussion}

The integrated TB model requires MTCM to be conducted by HCWs in PHC and is already being widely delivered in Chongqing. However, there is room for improvement. Although PHC sectors are required to deliver MTCM to outpatients, ${ }^{15}$ this study found that CDC (TB dispensaries) and MDR-TB designated hospitals also delivered MTCM during the outpatient phase. The integrated model requires that PHC sectors provide MDR-TB patients with standard case management (contacting patients at least 24 times during their treatment course), ${ }^{16}$ however, we found that only $60 \%$ of the patients received the required amount of 


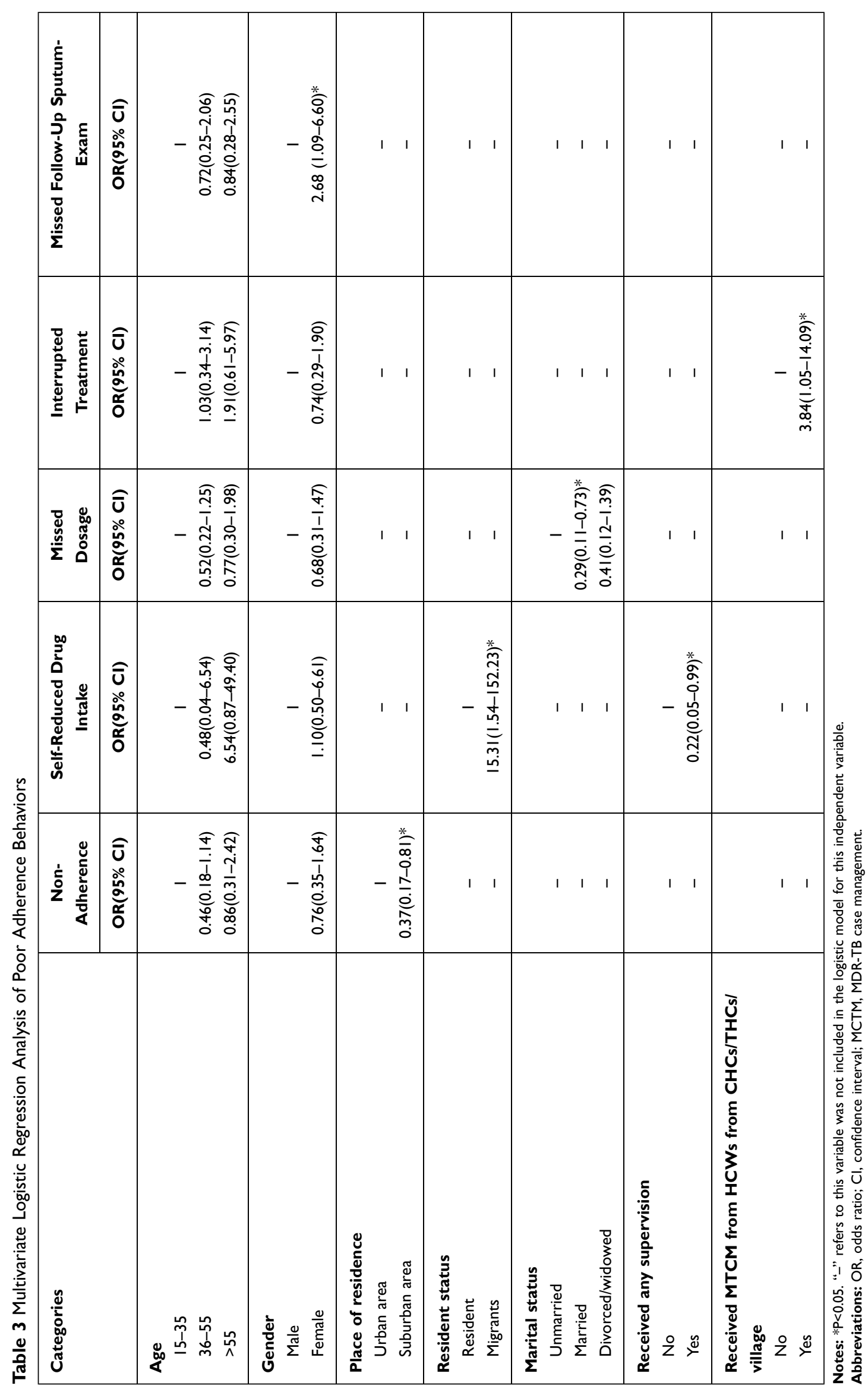


Table 4 Qualitative Results About MDR-TB Treatment Adherence and Management

\begin{tabular}{|c|c|c|}
\hline Themes & Results & Quotation \\
\hline $\begin{array}{l}\text { Patients' adherence with } \\
\text { MDR-TB treatment }\end{array}$ & $\begin{array}{l}\text { All MDR-TB patients, HCWs from PHC sectors and MDR-TB } \\
\text { designated hospitals reported poor adherence among MDR-TB } \\
\text { patients. }\end{array}$ & $\begin{array}{l}\text { "I stopped taking drugs after } 7 \text { or } 8 \text { months ... too much side- } \\
\text { effects caused me unable to adhere ... cough disappeared, so I } \\
\text { think I was cured"(MDR-TB patients) } \\
\text { "They cannot adherence with the treatment" (HCW from PHC } \\
\text { sector) } \\
\text { "About } 10 \% \text { patients cannot adherence with treatment" (HCW } \\
\text { from designated hospital) }\end{array}$ \\
\hline $\begin{array}{l}\text { Reasons for non-adherence } \\
\text { with MDR-TB treatment }\end{array}$ & $\begin{array}{l}\text { The most often mentioned reasons for interrupt treatment by } \\
\text { the MDR-TB patients, HCWs from PHC sectors and MDR-TB } \\
\text { designated hospitals were improvements in symptoms and side- } \\
\text { effects of drugs. Financial difficulty was also the reason though } \\
\text { there was special health insurance of reimbursement of } 90 \% \\
\text { treatment fee or } 50,000 \text { RMB per year. Individual HCWs from } \\
\text { MDR-TB designated hospitals reported that patients had poor } \\
\text { adherence because of busy with work. }\end{array}$ & $\begin{array}{l}\ldots \text { I stopped drugs after feeling better, ... my hands were so } \\
\text { swelling, painful, trembling, ... can't eat drugs anymore ... too } \\
\text { much side-effects ... I don't have money for follow-up } \\
\text { examinations, ... I can only borrow money from my daughter-in- } \\
\text { law (MDR-TB Patient) } \\
\text { “... there is one MDR-TB patient with liver cancer and drug- } \\
\text { related liver damage, he almost stopped treatment now” (HCW } \\
\text { from PHC sector) } \\
\text { “... but major symptoms disappeared, they believed they are } \\
\text { cured” (HCW from designated hospital) } \\
\text { “... some patients interrupted treatment due to busy work .... } \\
\text { some patients had financial difficult though there is the special } \\
\text { health insurance of reimbursement of } 90 \% \text { treatment fee or } \\
50,000 \text { RMB for MDR-TB patients in Chongqing, some patients } \\
\text { had multiple and server side-effects and could not adherence } \\
\text { with treatment”(HCW from designated hospital) }\end{array}$ \\
\hline $\begin{array}{l}\text { HCWs behaviours related to } \\
\text { MTCM }\end{array}$ & $\begin{array}{l}\text { All patients stated they received management by telephone from } \\
\text { HCWs in PHC sectors and they mainly received health education } \\
\text { on MDR-TB knowledge from HCW from MDR-TB designated } \\
\text { hospitals instead of HCWs from PHC sectors. } \\
\text { Though all HCWs in PHC sectors mentioned it is difficult to } \\
\text { manage MDR-TB patients comparing with drug-sensitive TB } \\
\text { patients, they delivered MDR-TB patients management according } \\
\text { to guideline. And they provided health education and } \\
\text { psychological counseling during home visits and telephone calls. } \\
\text { All HCW from MDR-TB designated hospitals claimed that they } \\
\text { would call patients to take follow-up examinations and pick } \\
\text { medicines, and they also provided health education to them. }\end{array}$ & $\begin{array}{l}\text { “... HCW from XX designed hospital told me to take medicine } \\
\text { one to two years at least ... pick drugs regularly ... during the } \\
\text { treatment period, only received telephone calls from HCWs in } \\
\text { PHC sectors once per month and asked me whether I felt better } \\
\text { and kept taking drugs”(MDR-TB patient) } \\
\text { “... HCW from designated hospital never called or home visited } \\
\text { me ... HCWs from PHC sectors called me ... this disease will } \\
\text { not cure if I interrupt the treatment ... they did not say about } \\
\text { side-effect ... HCW from PHC sector noticed me to get blood } \\
\text { test and liver function test ... called me and asked why I did not } \\
\text { take follow up”(MDR-TB patient) } \\
\text { “... we connected with patient, and conducted home visit ... } \\
\text { often called them, mainly for their medicine taking ... and their } \\
\text { psychological conditions, to communicated with them ... every } \\
\text { month ... most were phone calls ... for MDR-TB patients, three } \\
\text { times per month during the first six month ... once per month } \\
\text { for continues phase ... I provide health education to them during } \\
\text { home visit, and their families, e.g. dangerous of transmission ... } \\
\text { regular drug taking ... open windows at home ... close contacts } \\
\text { screening ... some patient have pressures, I would provide more } \\
\text { psychologically communications”(HCW from PHC sector) } \\
\text { “... we also provide health education when they consulted in } \\
\text { our hospital, eg, eating nutritionally ... preventing diseases } \\
\text { transmission, contacts screening”(HCW from designated } \\
\text { hospital) }\end{array}$ \\
\hline
\end{tabular}

(Continued) 
Table 4 (Continued).

\begin{tabular}{|c|c|c|}
\hline Themes & Results & Quotation \\
\hline $\begin{array}{l}\text { MDR-TB patients' willingness } \\
\text { to receive management by } \\
\text { HCWs in PHC sectors }\end{array}$ & $\begin{array}{l}\text { One MDR-TB patient expressed strong willingness to receive } \\
\text { management from HCWs in PHC sectors, but another patient } \\
\text { thought HCWs cannot help him. } \\
\text { All HCWs in PHC sectors mentioned that most patients } \\
\text { cooperated with management, and HCW from MDR-TB } \\
\text { designated hospitals mentioned MDR-TB patients trust more } \\
\text { HCWs from PHC sectors and possibly receive management from } \\
\text { them. } \\
\text { But HCWs from both PHC sectors and MDR-TB designated } \\
\text { hospitals reported some patients, especially the youths, do not } \\
\text { like to receive their management because of social stigma. }\end{array}$ & 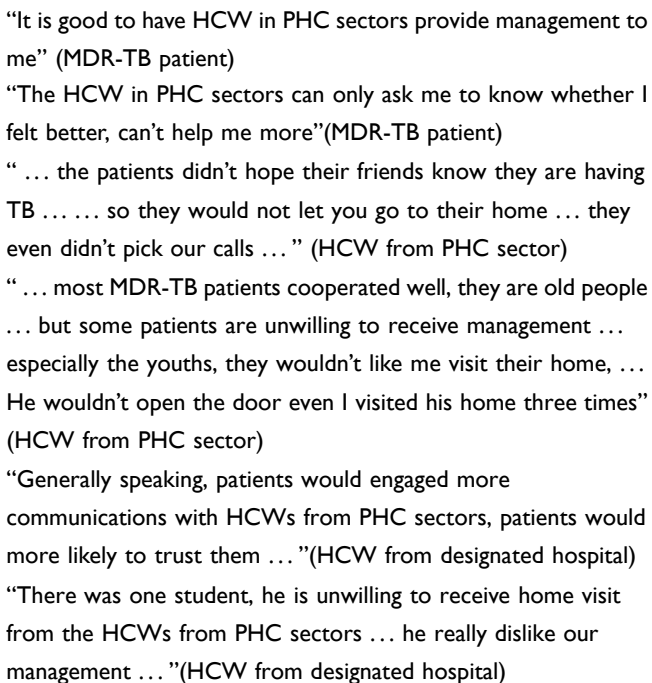 \\
\hline
\end{tabular}

Abbreviations: TB, tuberculosis; MDR-TB, multidrug-resistant tuberculosis; PHC, primary health care; HCWs, health care workers; MCTM, MDR-TB case management.

contact. Most case management was delivered via telephone only, indicating that MTCM implementation needs improvement. Our study also found that $62.5 \%$ of MDRTB patients exhibited non-adherence behaviors due to busy work schedules, negative drug side effects, lack of sputum production, financial difficulty, and the perception that adherence to treatment was unnecessary. These findings are consistent with previous studies. ${ }^{9,30,31}$ Receiving MTCM was found to be associated with a lower likelihood of reduced drug-intake, an important factor in the fight against MDR-TB. ${ }^{11,32-34}$

Several factors associated with poor adherence, such as negative side effects from treatment and the perception that adherence is unnecessary could be largely ameliorated through improved management methods and patient education. Our findings indicate that female, unmarried or migrant MDR-TB patients were more likely to have poor-adherence behaviors, and therefore efforts should be made to target these populations through MTCM. Another study found that married MDR-TB patients in Chongqing were at lower risk of missing a dose, possibly because they had more support from their families. ${ }^{35}$ It is also notable that patients from urban areas are less likely to receive MTCM, and more likely to have poor-adherence behaviors compared to those living in sub-urban areas, which also suggests the need to improve MTCM delivery to urban patients.
In our study, most MDR-TB patients received MTCM from HCWs in PHC sectors. However, our study suggests that MTCM delivered by HCWs in PHC sectors needs improvement in terms of both coverage and quality. The community-based care strategy proposed by WHO enables patients to receive treatment in the comfort and convenience of their own homes by well-trained community health workers, community staff and volunteers. ${ }^{36}$ This system allows patients and health care workers to develop strong relationships ${ }^{6,20,36}$ and offers patients a full course of Directly Observed Therapy (DOT). ${ }^{15}$ Multiple research studies ${ }^{4,5,20,37}$ have found this strategy to be effective in MDR-TB control. Our qualitative results also indicated that MTCM in PHC sectors should be provided as part of a comprehensive community-based care program, such as promoting health literacy, positive health behaviors, and optimizing health management services.

Our study found that HCWs in PHC sectors mainly implement MTCM through traditional methods such as telephone calls and home visits. However, many studies have emphasized the importance of exploring the use of innovative electronic health (e-health) technology in disease case management to improve patient adherence and treatment outcomes. $^{36,38-42}$ Some studies found it was easier to monitor adverse events and non-adherent behavior through mobile phone messaging, and one study in China found that using an electronic medication monitor (EMM) which provides regular reminders to take medication reduced poor-adherence behaviors. E-health management may be a more preferred 
management method ${ }^{42}$ and should be integrated into future MTCM delivery systems. This may be especially helpful in urban areas where people are more likely to accept modern technology.

This study has some limitations. As a retrospective survey, the recall bias is unavoidable, and since data on MDR-TB treatment outcomes were not included, we were unable to evaluate the impact of MTCM on MDR-TB treatment outcomes. Some factors associated with poor management or adherence behaviors, such as urban/suburban residence have not been fully explored. Future studies may further explore how different factors would influence MTCM delivery and adherence behaviors for MDR-TB patients, and investigate the impact of MTCM by HCWs in PHC sectors on MDR-TB treatment outcome.

\section{Conclusions}

MDR-TB treatment is expensive, lengthy, and can cause severe side effects. Addressing challenges in treatment adherence and MTCM is essential for MDR-TB control in Chongqing. Research on strategies which include community-based patient-centered models and the use of e-health technology could improve treatment adherence and the effectiveness of MTCM.

\section{Abbreviations}

$\mathrm{CDC}$, centers of disease control; $\mathrm{CHCs}$, Community Health Centers; CPHMC, Chongqing Public Health Medical Center; CIS-DCP, China Information System for Disease Control and Prevention; HCWs, Health Care Workers; INH, Isoniazid; MDR-TB, Multidrug-resistant Tuberculosis; MTCM, MDR-TB Case Management; NTP, National Tuberculosis Control Programme; PHC, Primary Health Care; RFP, Rifampicin; RR-TB, Rifampicin-resistant Tuberculosis; TB, Tuberculosis; THCs, Township Hospital Centers; WHO, World Health Organization; XDR-TB, Extensively Drug-resistant Tuberculosis.

\section{Data Sharing Statement}

Data sharing is not applicable to this article as no datasets were generated or analyzed during the study.

\section{Ethical Approval and Consent to Participate}

The project was approved by the Institutional Review Board of Army Medical University, Chongqing, China, and was conducted in accordance with the Declaration of Helsinki. All participants gave their written informed consent to participate, and parental consent was obtained for participants under the age of 18 .

\section{Acknowledgments}

The authors would like to thank all the patients, TB doctors and healthcare workers who participated in this study.

\section{Author Contributions}

All authors made a significant contribution to the work reported, whether that is in the conception, study design, execution, acquisition of data, analysis and interpretation, or in all these areas; took part in drafting, revising or critically reviewing the article; gave final approval of the version to be published; have agreed on the journal to which the article has been submitted; and agree to be accountable for all aspects of the work.

\section{Funding}

This project was funded by the National Natural Science Foundation of China (No. 81773489), the Chongqing outstanding youth project (cstc2020jcyj-jqX0007), Social Science and Technology Innovation Subject in Chongqing (No. cstc2015shmszx120070), and the 2019 Chongqing Municipal Health and Health Committee \& Chongqing Science and Technology Bureau Joint Medical Research Project (No. 2019MSXM095). The funder had no role in study design, data collection and analysis, decision to publish, or preparation of the manuscript.

\section{Disclosure}

The authors declare that they have no competing interests.

\section{References}

1. WHO. Global Tuberculosis Report, 2020. Geneva: World Health Organization; July, 2020. Available from: https://www.who.int/. Accessed February 25, 2021.

2. WHO. The End TB Strategy. Geneva: World Health Organization; 2014. Available from: https://www.who.int/. Accessed July, 2020.

3. Cheng SM. Current situation and recommendation of MDR-TB prevention and control in China. China Trop Med. 2017;17(3):213-215.

4. Loveday M, Wallengren K, Brust J, et al. Community-based care vs. centralized hospitalization for MDR-TB patients, KwaZulu-Natal, South Africa. Int $J$ Tuberc Lung Dis. 2015;19(2):163-171. doi:10.5588/ijtld.14.0369

5. Wai PP, Shewade HD, Kyaw NTT, et al. Community based MDR-TB care project improves treatment initiation in patients diagnosed with MDR-TB in Myanmar. PLoS One. 2018;13(3):e0194087. doi:10.1371/ journal.pone.0194087

6. Oyieng'o D, Park P, Gardner A, et al. Community-based treatment of multidrug-resistant tuberculosis: early experience and results from Western Kenya. Public Health Action. 2012;2(2):38-42. doi:10.5588/pha.12.0002 
7. Zou GY, Wei XL, Walley JD, et al. Factors influencing integration of TB services in general hospitals in two regions of China: a qualitative study. BMC Health Serv Res. 2012;12(1):21. doi:10.1186/1472-6963-12-21

8. Li Y, Ehiri J, Oren E, et al. Are we doing enough to stem the tide of acquired MDR-TB in countries with high TB burden? Results of a mixed method study in Chongqing, China. PLoS One. 2014;9(2): E88330. doi:10.1371/journal.pone.0088330

9. Tadesse T, Demissie M, Berhane Y, et al. Long distance travelling and financial burdens discourage tuberculosis DOTs treatment initiation and compliance in Ethiopia: a qualitative study. BMC Public Health. 2013;13(1):424. doi:10.1186/1471-2458-13-424

10. Wynne A, Richter S, Banura L, Kipp W. Challenges in tuberculosis care in Western Uganda: health care worker and patient perspectives. Int J Afr Nurs Sci. 2014;1(C):6-10. doi:10.1016/j.ijans.2014.05.001

11. Bastos ML, Cosme LB, Fregona G, et al. Treatment outcomes of MDR-tuberculosis patients in Brazil: a retrospective cohort analysis. BMC Infect Dis. 2017;17(1):718. doi:10.1186/s12879-017-2810-1

12. Liu YH, Wu JG, Zhou GZ, et al. Influencing factors for treatment adherence of patients with multidrug resistant tuberculosis. Chin $J$ Infect Control. 2015;9:593-596.

13. Ren SJ. Investigation and study of influence of treatment adherence after discharge with MDR-TB patient. China Health Stand Manage. 2016;12.

14. Qian ML. Study on the influencing factors and countermeasures of treatment compliance in patients with multidrug-resistant tuberculosis. Chin Foreign Med Treat. 2015;22.

15. Ministry of Health of PRC. National tuberculosis control programme (2011-2015). Available from: http://www.gov.cn/gongbao/content/ 2011/content_2020914.htm. Accessed July, 2020.

16. General office of the state council: national tuberculosis control plan (2011-2015). 2011. Available from: http://www.gov.cn/zwgk/201112/06/content_2012869.htm. Accessed July 2020.

17. Wei XL, Zou GY, Yin J, Walley J, Sun Q. Comparing patient care seeking pathways in three models of hospital and TB programme collaboration in China. BMC Infect Dis. 2013;13(1):93. doi:10.1186/ 1471-2334-13-93

18. Sun Q, Yin J, Yin X, et al. Does the integration of TB medical services in the general hospital improve the quality of TB care? Evidence from a case study in China. J Public Health. 2013;35 (2):322-328. doi:10.1093/pubmed/fds089

19. Xu WX, Hu J, Luo YJ. Preliminary evaluation of the treatment effect of drug-resistant tuberculosis patients in Jiaxing City. China Rural Health Serv Administration. 2014;34(03):288-289.

20. Heller T, Lessells RJ, Wallrauch CG, et al. Community-based treatment for multidrug-resistant tuberculosis in rural KwaZulu-Natal, South Africa. Int J Tuberc Lung Dis. 2010;14(4):420-426.

21. Jelly I, Peters M. Community-based management of multiple drug resistant tuberculosis in a tertiary hospital in Tanzania: a best practice implementation project. JBI Database System Rev Implement Rep. 2017;15(12):3092-3101. doi:10.11124/JBISRIR-2017-003390

22. Liu Y, Liu J, Jing KH, et al. Analysis on monitoring results of resistance of anti-tuberculosis drug in Chongqing. Mod Prev Med. 2012;39:692-694.

23. Wang XY, Luo M, Zhang HZ, Wang J. Correlation analysis between rifampicin resistance and multidrug resistance in tuberculosis patients in Chongqing. China Trop Med. 2019;12.

24. Farrugia B. WASP (write a scientific paper): sampling in qualitative research. Early Hum Dev. 2019;133:69-71. doi:10.1016/j. earlhumdev.2019.03.016

25. Smith J, Firth J. Qualitative data analysis: the framework approach. Nurs Res. 2011;18(2):52-62. doi:10.7748/nr2011.01.18.2.52.c8284

26. Srivastava A, Thomson SB. Framework analysis: a qualitative methodology for applied policy research. $J$ Administration Governance. 2009;4(2):72-79.

27. Ward DJ, Furber C, Tierney S, Swallow V. Using framework analysis in nursing research: a worked example. J Adv Nurs. 2013;69 (11):2423-2431. doi:10.1111/jan.12127
28. World Health Organization. Treatment of Tuberculosis: Guidelines for National Programmes. Geneva, Switzerland: World Health Organization; 1997. Available from: https://www.researchgate.net/publication/ 274519736_Book_Reviews_Treatment_of_Tuberculosis_guidelines_for_ national_programmes_4th_Edition_By_The_World_Health_Organization Published by WHO Press 2010 Paperback 157pp Price 2500 ISBN 978 92 4_154783 3? ev=auth pub. Accessed July, 2020.

29. Wang LX, Cheng SM, Chen MT, et al. Report on the fifth national tuberculosis epidemiological survey in 2010. Chin J Antituberculosis. 2012;8. Available from: https://kns.cnki.net/kcms/detail/detail.aspx? $\mathrm{d} b \mathrm{code}=\mathrm{C} \mathrm{JFD} \& \mathrm{~d}$ bn a m e $=$ C JF D $2012 \&$ fi 1 e n a me $=$ Z F L Z $201208002 \&$ v = Y q w 4 a Q 4 y B Xf 6 b z P u 0 f A \% 25mmd2F0kyPEz63ARf39GLB7k6eXeGIsvqzElxJBAj5nFQecknW. Accessed February 25, 2021.

30. Zheng L, Xu HL, Yang KY. Study on the Treatment Adherence and Its Influencing Factors of Multidrug-Resistant Tuberculosis (TB) Patients in the Tuberculosis Hospital of Hunan Province. Zhongnan University; 2014. Available from: https://kns.cnki.net $/ \mathrm{kcms} /$ detail/ detail.asp $x$ ?dbcode $=$ CMFD \&dbname $=$ CMFD201401\&filename $=$ $1014144715 . n h \& v=1 Z Y$ KyFmSRjrgP $6 \% 25 \mathrm{mmd} 2 \mathrm{FR} 61 \mathrm{i} \%$ $25 \mathrm{mmd} 2 \mathrm{~B} \mathrm{Ex} \mathrm{J} 9 \mathrm{c}$ i a W d E C v 4 x B \% $25 \mathrm{~mm} \mathrm{~d} 2$ F D w Z W \% 25mmd2BjjBp8RTHqIoJLxu4PzPbPLn. Accessed July, 2020.

31. Hao BL, Liu ZF, Ma LP. Univariate analysis of the factors affecting treatment adherence of 98 multidrug-resistant tuberculosis patients. Henan J Prev Med. 2014;4.

32. Pablos-Méndez A, Knirsch CA, Barr RG, Lerner BH, Frieden TR. Nonadherence in tuberculosis treatment: predictors and consequences in New York City. Am J Med. 1997;102:164-170. doi:10.1016/S0002-9343 (96)00402-0

33. Sharma SK, Turaga KK, Balamurugan A, et al. Clinical and genetic risk factors for the development of multi-drug resistant tuberculosis in non-HIV infected patients at a tertiary care center in India: a case-control study. Infect Genet Evol. 2003;3:183-188. doi:10.1016/S1567-1348(03)00086-8

34. Gelmanova IY, Keshavjee S, Golubchikova VT, et al. Barriers to successful tuberculosis treatment in Tomsk, Russian Federation: nonadherence, default and the acquisition of multidrug resistance. Bull World Heal Organ. 2007;85:703-711. doi:10.2471/BLT.06.038331

35. Zhang W, Hu DY, Liu Y, et al. Prevalence of multidrug-resistance in 638 tuberculosis patients in Chongqing. China Trop Med. 2017;3:231-235.

36. WHO. WHO Companion Handbook to the Who Guidelines for the Programmatic Management of Drug-Resistant Tuberculosis. Geneva: World Health Organization; 2014. Available from: https://pubmed. ncbi.nlm.nih.gov/25320836/. Accessed July, 2020.

37. Zhou L, Chai CL, Chen SH, et al. Analysis of the outcome of communitymanaged multidrug-resistant tuberculosis patients. Prev Med. 2017;1.

38. Lewis JJ, Liu X, Zhang Z, et al. Evaluation of a medication monitorbased treatment strategy for drug-sensitive tuberculosis patients in China: study protocol for a cluster randomised controlled trial. Trials. 2018;19(1):1-12. doi:10.1186/s13063-018-2650-3

39. Chaiyachati K, Loveday M, Lorenz S, et al. A pilot study of an mhealth application for healthcare workers: poor uptake despite high reported acceptability at a rural South African communitybased MDR-TB treatment program. PLoS One. 2013;8(5):E64662. doi:10.1371/journal.pone.0064662

40. Do D, Garfein R, Cuevas-Mota J, Collins K, Liu L. Change in patient comfort using mobile phones following the use of an app to monitor tuberculosis treatment adherence: longitudinal Study. JMIR Mhealth Uhealth. 2019;7(2):E11638. doi:10.2196/11638

41. Liu X, Lewis JJ, Zhang H, et al. Effectiveness of electronic reminders to improve medication adherence in tuberculosis patients: a clusterrandomised trial. PLoS Med. 2015;12(9):E1001876. doi:10.1371/ journal.pmed.1001876

42. Wei X, Hicks JP, Pasang P, et al. Protocol for a randomised controlled trial to evaluate the effectiveness of improving tuberculosis patients' treatment adherence via electronic monitors and an app versus usual care in Tibet. Trials. 2019;20(1):273. doi:10.1186/s13063-019-3364-х 


\section{Publish your work in this journal}

Infection and Drug Resistance is an international, peer-reviewed openaccess journal that focuses on the optimal treatment of infection (bacterial, fungal and viral) and the development and institution of preventive strategies to minimize the development and spread of resistance. The journal is specifically concerned with the epidemiology of antibiotic resistance and the mechanisms of resistance development and diffusion in both hospitals and the community. The manuscript management system is completely online and includes a very quick and fair peerreview system, which is all easy to use. Visit http://www.dovepress.com/ testimonials.php to read real quotes from published authors. 